\title{
Mathematical Art as a Discipline
} Frank A. Farris

Every year, more people become involved in making mathematical art. More than a vehicle for outreach or a methodology for discovery, mathematical art has become a discipline in its own right, with community norms, journals, and conferences. In this article, I explain how our mathematical community will benefit from devoting resources to foster and amplify the lively interdisciplinary interactions between mathematics and art that promise to become even more exciting in years to come.

The crescendo of energy for mathematical art comes at a time when many are concerned about access to mathematics, a concern connected to public perception of mathematics. The mathematical artist, when recognized as a distinctive type of interdisciplinary scholar, can help our community attract the next generation of talent, while also showing the public that mathematical beauty is available to everyone. Just as there are ordinary, work-a-day mathematicians and the Fields medalists, there will be mathematical artists remembered a century from now and others who get credit for modest output. This is the nature of the academy, but the process of honoring the greatest accomplishments and acknowledging minor ones begins by recognizing that there is actually a discipline here.

As with any nascent discipline, mathematical art is still finding its way. What career path should a next-generation of mathematical artists pursue? This is not for me to

Frank A. Farris is a professor of mathematics and computer science at Santa Clara University. His email address is ffarris@scu.edu.

For permission to reprint this article, please contact:

reprint-permission@ams.org.

DOI: https://doi.org/10.1090/noti2296 say. Instead, I give some history, mentioning many key mathematical artists whom I admire greatly. Then I outline my own path through this landscape, to help readers see my perspective. With this background, I describe various dimensions of the value of mathematical art. I hope that these observations might have some effect on the academy, but, more importantly, I hope they will inspire young mathematicians to consider becoming involved in the meaningful work of leveraging mathematics to make art.

\section{Milestones in Mathematical Art}

Mathematical art took a wonderful upturn when Reza Sarhangi and others founded the Bridges Organization in 1998 (bridgesmathart.org/reza-sarhangi/). Running strong as an online event in the summer of 2021 (bridgesmathart.org/bridges-2021/), the Bridges Conference brings mathematicians together with artists from many disciplines. The art exhibition at Bridges is one of two principal venues for mathematical artists to share their work and get feedback, the other being the AMS Mathematical Art Exhibition at the JMM every year (ga17ery.bridgesmathart.org/exhibitions/2021 -joint-mathematics-meetings). Though Sarhangi died in 2016, his energy lives on in the warmth of the Bridges community.

Another notable development was the founding of the Mathematical Association of America Special Interest Group on the Arts (SIGMAA Arts) in 2006. This group provides opportunities for mathematical artists to present their work, although neither the organization nor the sessions they organize are exclusively devoted to the subject. 
Each year at the JMM, the seemingly overflowing SIGMAA Arts sessions include many talks by mathematical artists, but also a significant number of papers about using various kinds of art to support the teaching of mathematics. Like many other groups, SIGMAA Arts will need to navigate the new relationship between the MAA and the JMM. Since the art exhibition is sponsored by the AMS, the JMM is the natural meeting for activities of this MAA-sponsored group.

On the AMS side, the appointment of Annette Emerson as Public Awareness Officer in 2001 turned out to be quite significant for mathematical artists. Emerson seems to have been the driving force behind several connected events. An annual JMM Mathematical Art Exhibit started small in 2004 and grew steadily. Emerson leveraged this energy to produce a Mathematical Imagery gallery on the AMS website, with annual calendars starting in 2011. The Mathematical Art Exhibition Award was endowed in 2008 to recognize those "whose works demonstrate the beauty and elegance of mathematics expressed in a visual art form." This provided welcome evidence of the value of mathematical art to the broader mathematical community.

\section{Events at ICERM}

In 2016, the NSF made a bold move to support visualization and the related discipline of mathematical art by approving some significant funding: The Institute for Computational and Experimental Research in Mathematics (ICERM) held a week-long workshop called Illustrating Mathematics. The opening three sentences of the descriptive abstract were exactly what I wanted to hear:

Research and outreach are normally thought to divide mathematics in two. This separation is, however, completely artificial; it is impossible to "find" a mathematical idea without explaining it. Exploration and exposition are two sides of the same coin.

The rigors of NSF review probably required the organizers to explain how this workshop would lead to new theorems, but it was refreshing to hear that illustration could be a research activity, valued in its own right. I have long questioned the way our community has privileged acts of discovering the first proof of a theorem over acts of explaining and illustrating it. Shouldn't finding a novel, or even an especially beautiful, way to picture something count as much as finding the first way to prove that it is true?

Perhaps on the strength of my 2015 book [Far15], I was accepted for the Illustrating Mathematics workshop in 2016. The company was inspiring. Jeff Weeks told us about his Geometry Games website; Jesse Louis-Rosenberg and Jessica Rosenkrantz, principals in an architectural firm called Nervous System, showed a video of their first
3D-printed dress; Edmund Harriss showed how he had hacked an industrial router to make mathematical sculptures. During my talk about continuous methods for mathematical art, Mikael Vejdemo Johansson wrote a Twitterbot, @symmetric_curve, that uses the formula from one of my introductory examples [Far96] to spit out a new animated symmetric curve every four hours. It was a remarkable workshop.

When ICERM announced a semester-long workshop, also called Illustrating Mathematics, for Fall 2019, I knew I had to attend and took steps to be there, against heavy odds. How fortunate we were to be together in Providence, before the COVID-19 pandemic set in and the world changed so! The list of organizers is a who's who of experts in visualization: David Bachman, Kelly Delp, David Dumas, Saul Schleimer, Richard Schwartz, Henry Segerman, Katherine Stange, and Laura Taalman. Under their leadership, about 46 of us were able to stay for the whole semester. Any one of us would tell you that it was a transformative experience.

About four times during the fall, for week-long special workshops, our population would approximately double. Overall, the program hosted 255 visitors! During workshops, there would be five hour-long talks each day, most of which are now available to view through the ICERM website. Some of the speakers were mainstream mathematicians, focused on using visualization to find the next theorem to prove. Others were mainstream artists, some of these more and some less able to articulate their connections to mathematics. Many of us count ourselves as mathematical artists and it was a good time for everyone to ponder what that means.

Fortunately, it is not necessary for me to try to mention all the visitors, because Diana Davis has edited an attractive volume called Illustrating Mathematics [Dav20] to do just that. Davis gives each participant a page to describe their work facing a page to show the work. Two of my favorites are Silviana Amethyst's realizations of Barth's sextic and Bernat Espigulé's tree-like 3D prints of families of fractal sets.

Let me relate two stories from the semester at ICERM, with a preference for reporting events that touched a little more on the artistic side than the strictly mathematical one. I regret that space does not permit me to tell such stories as how Henry Segerman, Steve Trettel, and others used virtual reality to explore strange geometries, or how Aaron Abrams and Stepan Paul made paper with negative curvature for hyperbolic origami.

WaterFire. If you've spent time in Providence, you might know about WaterFire, the recurring nighttime festival that features fires floating in the two rivers that converge just upstream from where ICERM is housed at Brown University. It is my favorite public event in the US and I was 


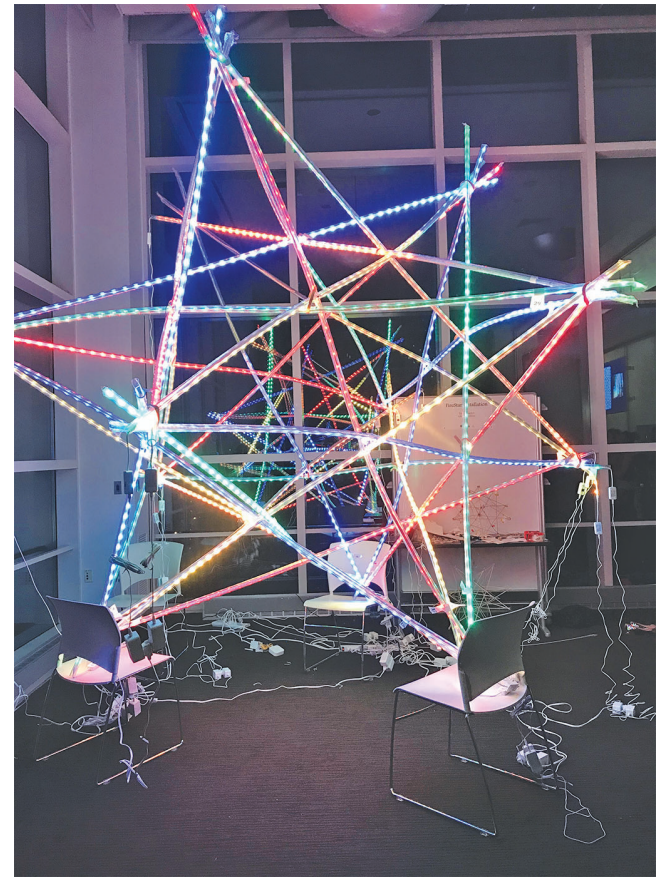

Figure 1. A public art installation by Glen Whitney, shining some mathematical art from the windows of ICERM.

delighted to learn that the Illustrating Mathematics organizers planned an evening of public art on a WaterFire evening early in our term. We reconfigured the lecture hall, with its ample windows looking out over the festival, into a public space with display tables all around the perimeter.

As a primarily digital artist, I was short on hands-on activities, so I offered a couple of movies-vibrating wallpaper and rotating woven polyhedral shapes-with some quiet background music. The real energy was provided by those offering opportunities to interact with things. Edmund Harriss had large polyhedral constructions from his Curvahedra pieces, which will pop right back into shape if you compress them. John Edmark had one of his Blooms machines, creating an illusion of blooming by strobing a spinning 3D-printed sculpture whose design uses the mathematics of Fibonacci spirals. Passing by his station, I marveled at how many times Edmark must have patiently explained the concept of the golden angle to curious listeners, captivated by the magic of his sculptures, which seem to grow magically. In one large corner of the room, Glen Whitney supervised the assembly of a marvelous structure he had designed, a stellated dodecahedron strung with lights that could change color according to the instructions of a microprocessor. Figure 1 shows the assembled structure, all wired up to flash a dramatic invitation to mathematics above the public festival.

The whole event was outreach at its finest and an artistic creation in its own right. People stayed long after the scheduled closing, in order to watch Whitney run the lights in his sculpture through their paces.

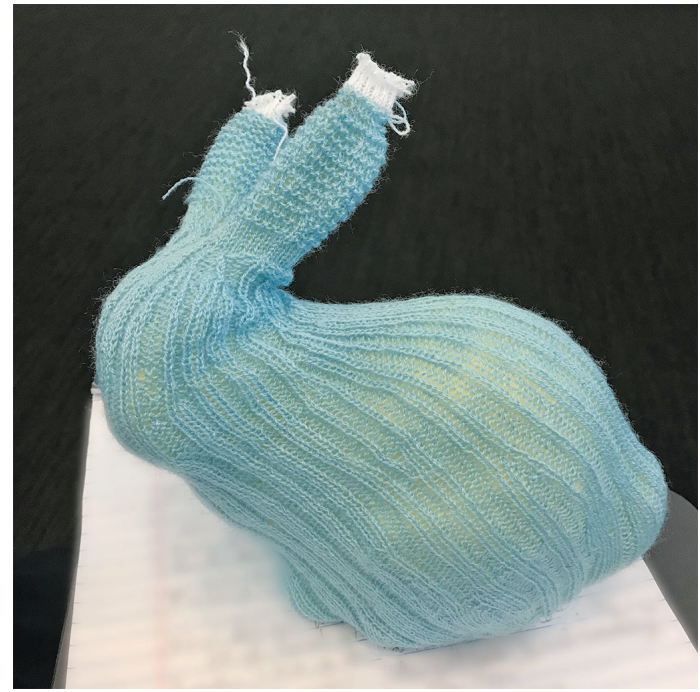

Figure 2. The Stanford Bunny realized via mechanical knitting, by Jim McKann of Carnegie Mellon University.

Computational Textiles Week. Identifying myself primarily as a geometer, I expected the week-long workshop "Illustrating Geometry and Topology," in the third week of the semester, to be the high point. It was intense and did indeed send me off on fruitful investigations, but it was the "Computational Textiles Working Group" the following week that brought the most unexpected new ideas. Key organizer Sabetta Matsumoto coordinates an interdisciplinary group at Georgia Tech to study the mechanical properties of knit fabrics, among other things. I thought it would be interesting, but not really in my area.

That said, I was intrigued by one of the stated goals of the working group: "We would like to explore the idea that knitting and textiles can be a physical embodiment of ideas in computational geometry." The first talk, by Jim McKann of Carnegie Mellon University, was called "The Future of Knitting Machine Programming." He outlined a process whereby a network of knit stitches could be derived from a mesh, which is the fundamental object computational geometers use to describe surfaces. He created a fine moment of excitement by revealing a mechanically knitted version of the Stanford Bunny, a staple of graphics demonstrations, shown in Figure 2.

After a short break, Susan Goldstine of St. Mary's College of Maryland gave her talk, "Yarn, Stitch, Fabric: Searching for a Theory of Knitted Lace Symmetry." It became clear that the question, "What is a stitch?" remains a live one. Goldstine has won acclaim for her numerous entries in the Mathematical Art Exhibition and contributions to Bridges. Exemplifying the mathematical artist who likes to create a collection of "one of each type," she has made various samplers of all frieze and wallpaper patterns that can be realized in a given medium. Figure 3 shows one such sampler, where the symmetry diagrams for the friezes are cleverly knit into the sampler with colored beads 


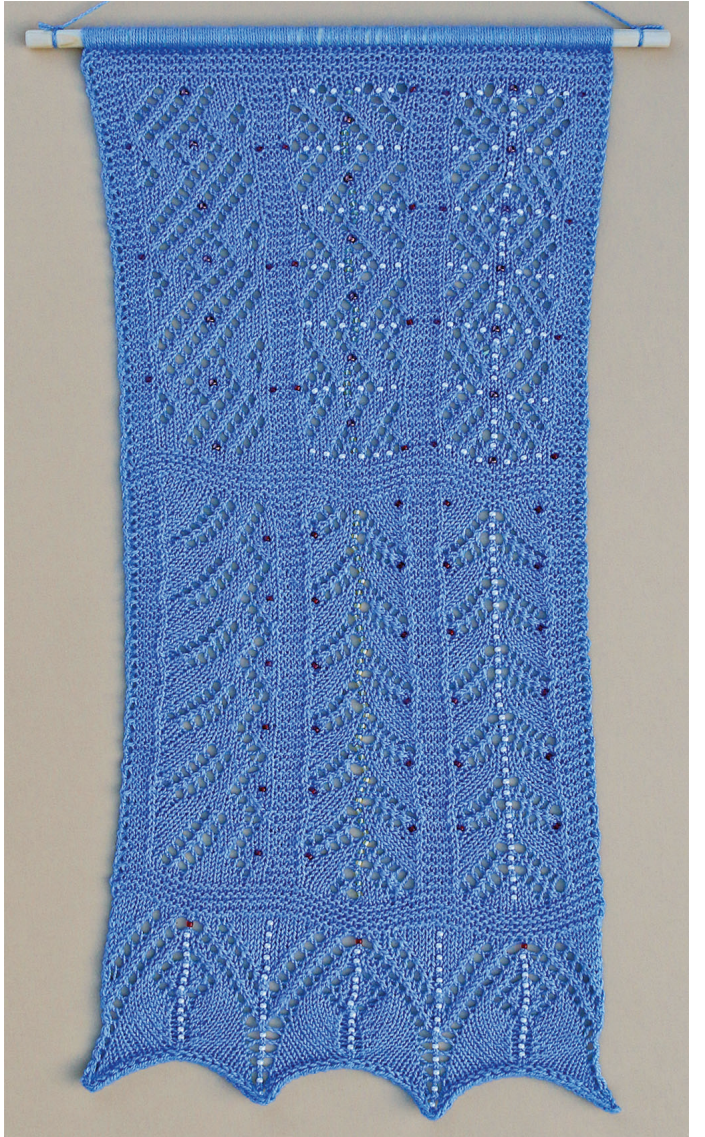

Figure 3. "The Symmetry Diagrams Themselves," (Merino/silk yarn, glass beads, 2018) a sampler of all possible frieze pattern types, by Susan Goldstine.

(gallery.bridgesmathart.org/exhibitions/2018 -bridges-conference/sgoldstine). Examine Figure 3 to see how beads indicate mirror and glide axes, as well as centers of 2-fold rotational symmetry.

It was Rebecca Field's talk, on the "physical properties of hyperbolic space in relation to the history of clothing and armor" that set me off on my most fruitful tangent at ICERM. Field, of James Madison University, passed around a wonderfully heavy sample of steel chain mail and talked about her efforts to make a similar 3D-printed material from collections of linked circles.

All this time, I had been learning to use Grasshopper, a mathematically friendly plug-in to an architectural design program called Rhino. (Free versions of some of these products are available; the interested reader can investigate Blender and Sverchok.) Dave Bachman had given an introduction to Grasshopper at the 2016 workshop and proved a patient teacher for anyone who wanted to learn during our semester in 2019. Before hearing Field's talk, I had already implemented the basic knit stitches in Grasshopper; Figure 4 shows ribbing, the pattern obtained by alternating knits and purls as you proceed along a row. It popped into my head to ask, "What if I could make wallpaper patterns in
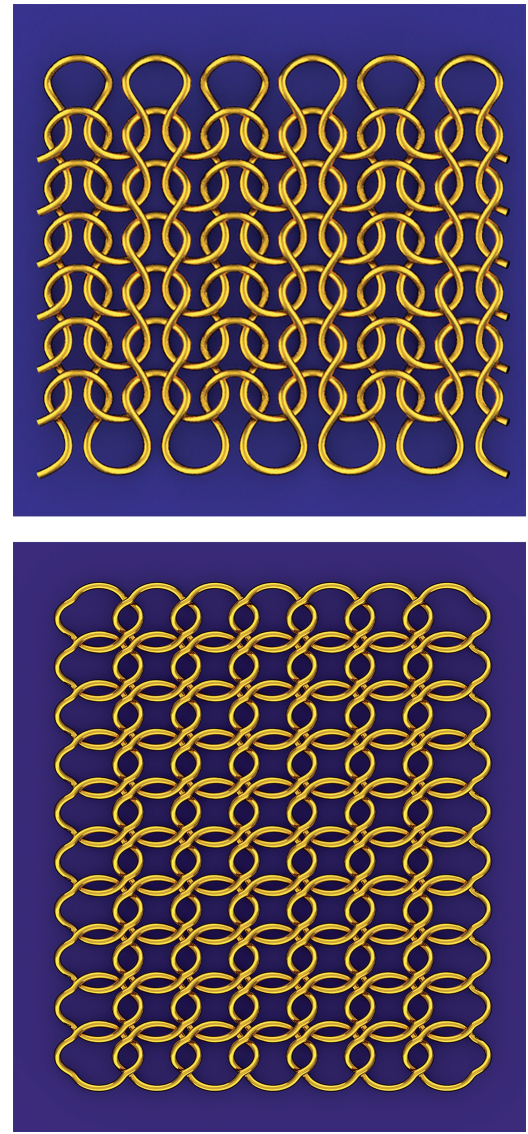

Figure 4. Top: Emulating the ribbing stitch in Rhino with Grasshopper. Bottom: Mathematical chain mail.

chain mail from rings that aren't necessarily circles?" Just a few weeks later, I had printed my first examples, with helpful assistance from our 3D-printing guru, Laura Taalman of James Madison University.

This body of work turned into my paper, "Wallpaper patterns from non-planar chain mail links," for the 2020 Bridges conference. I think it's some of my best work. A representative example of wallpaper chain mail is shown in Figure 4.

\section{My Own Experience}

How did I enter the world of mathematical art? For personal reasons, in the mid-'90s, I felt the need to reinvent myself as a mathematician. My most productive work, especially a project I began with Tom Banchoff during a 1991 sabbatical [BF93], had drawn on my long-time love of visualization. Indeed, I had taken every computer I had ever owned to the edges of what it could do in the way of mathematical graphics. For instance, my Commodore 64 cranked out phase portraits for nonlinear ODEs back in the mid-' 80 s.

An accidental encounter with symmetry in plane curves [Far96] grabbed my attention, and soon I found myself working out a basis for all the standing waves of a planar 
membrane that had, instead of boundary values, a wallpaper symmetry condition. Answering that mathematical question and using it to create images felt like my first real act as a mathematical artist. As I worked to make the images more beautiful, and less like diagrams, I felt that I was doing something new.

Figure 5 shows two wallpaper patterns based on complex-valued wallpaper functions and photographs, using the domain coloring algorithm, a term that I coined in 1996. In each case, a particular wave function with wallpaper symmetry returns a complex number at each point in the computed image; that complex number identifies the content of a pixel in the photograph by assigning a complex coordinate there. Since the functions are smooth, the features of the pattern appear to be deformations of the photograph. For instance, the pumpkin pie in the first inset seems to have morphed into an overly symmetric carousel horse; the clouds in the second inset lift up as angel wings. My first efforts to make designs like these were quite primitive by comparison.

In the late'90s, I gave a colloquium on this work, which eventually led to my book, Creating Symmery, The Artful Mathematics of Wallpaper Patterns, published by Princeton University Press [Far15]. Paul Halmos was in the audience. He asked me if my work would have any meaning independent of the images I showed. This is an interesting question. My answer at the time was that, yes, it is interesting to write out bases for the various spaces of functions invariant under the action of wallpaper groups on the plane, but that, no, I probably wouldn't care about that result if I didn't have technology for turning it into images that I found breathtakingly beautiful. I couldn't help believing that my value as a mathematician sank in his assessment. For me, the potential of these things to become beautiful gave them significance; for Halmos, not so much.

Just as mathematical publications are appropriately tested by peer review, so are artworks judged by informed practitioners. Since I started following my convictions and pursuing activities like the wallpaper project, I have been invited to present more than half a dozen academic exhibitions of my artwork, all named as variations of "SymmetryScapes." My artworks have been accepted in juried shows. I was awarded first prize for Best Photograph, Print, or Painting in the Mathematical Art Exhibition at the JMM in 2018.

Working over twenty-five years to learn how to develop and present artistic works, while also continuing to pursue new mathematical methods in the service of art and illustration, I now have some credibility as a mathematical artist. Still, I hope that the next generation of mathematical artists will not arrive by quite such a strange path as mine.
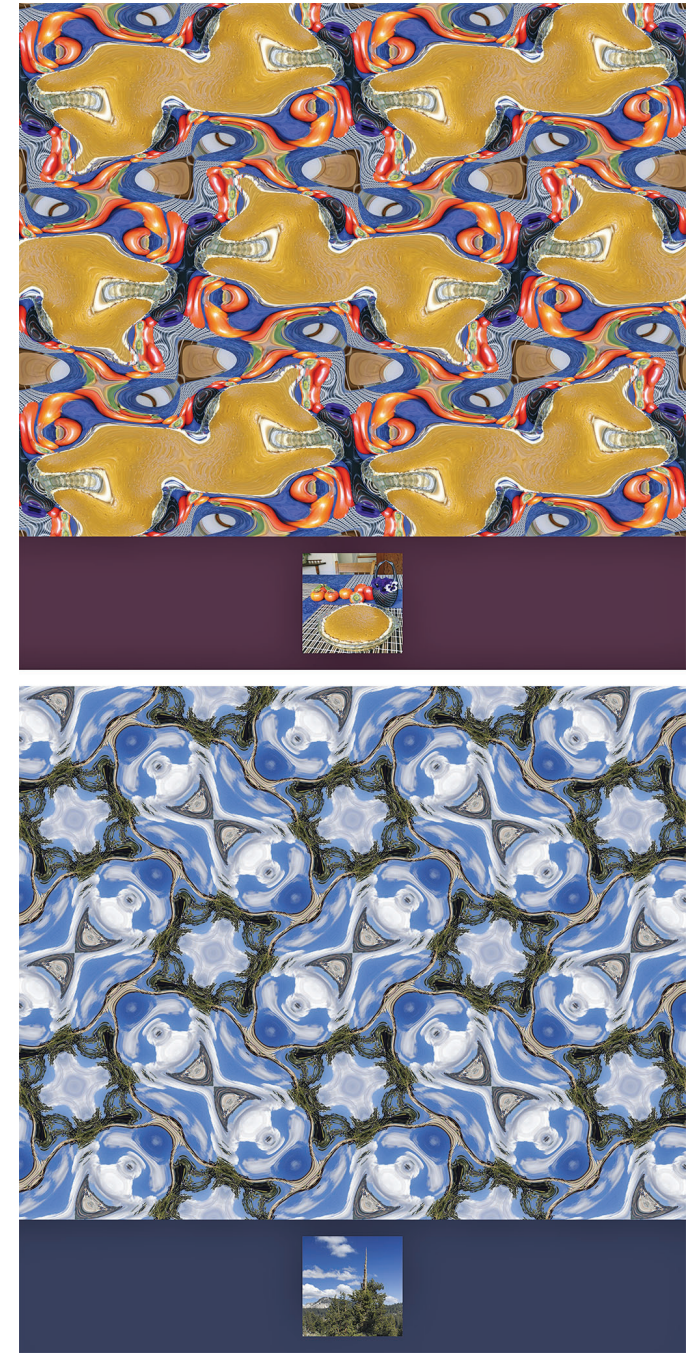

Figure 5. Two wallpaper patterns using standing waves and the photograph shown in the inset. (a) "Carousel Horses from Pumpkin Pie," digital print on aluminum, 20" by 20," 2015. (b) "Angel Clouds from a Lone Tree," digital print on aluminum, 20 " by 20," 2016.

\section{The Value of Mathematical Art}

What does it matter that I have made lovely patterns and written careful instructions to show others how to make, in many cases, every possible example of that type of pattern? The things that I make do indeed delight me and I have no plans to stop seeking that experience of wonder that comes when things fall into place just so. But my real hope is that more institutions support the activity of making mathematical art. How far are we from a world where a department could hire a mathematical artist just as they would another kind of mathematician? There are several potential gains when the number of practicing mathematical artists grows: new entryways to mathematics, a more positive perception of mathematics as a human activity, a wealth of creative assignments for our students, and substantial growth in our understanding of mathematics itself. 
A way into mathematics. Many in our mathematical community are awaking to a desperate need to provide better ways to invite people in, to create more accessible entryways to mathematical activity. I fear that the approach I saw as a student in the 20th-century, with its emphasis on manipulating symbols and solving difficult problems out of context, excludes people who might thrive in mathematics, solving difficult problems and manipulating those symbols with joy, if only they had first been able to experience the beauty of mathematics.

When mathematical artists gain visibility, it helps young people see that they can become mathematicians by taking delight in mathematics, whether through visual art or some other medium.

You may have guessed that I am deeply influenced by Francis Su's book, Mathematics for Human Flourishing. I recommend it highly. Inspired by Su, I have assigned my geometry students to write essays about Beauty and make their own artworks. I've invited them to engage in Play by puzzling over some of the charming problems that appear every few days from Catriona Shearer (now Catriona Agg) on Twitter, @Cshearer41. If we are looking for one kind of person, exclusion works fine. Surely, we are looking for a wide variety of people to become mathematicians, so we must offer that same wide variety of ways to join in.

Public perception. Apart from the fact that we sometimes close the door on someone who might do very well among us, our community has a problem with how society at large tends to perceive us. Even when a young person shows a conventional talent for mathematics, they could be turned off if the prejudice of a parent or peer warns them away. In order to include all who might succeed in mathematics, our community needs to present to the whole world a face of mathematics that offers both wonder and welcome. This is what leads me to say over and over again, "Look at these beautiful things!" and I am grateful for everyone who has devoted resources to amplifying this message.

Annette Emerson has retired from the AMS, but her work to highlight mathematical art to interest and inform the public will be taken up by others. The recent books by Stephen Ornes (Math Art: Truth, Beauty, and Equations [Orn19]) and Lynn Gamwell (Mathematics + Art: A Cultural History [Gam16]) are evidence that publishers see a demand for information about the topic. I assert, however, that these efforts will remain a pretty window-dressing unless the mathematical community shows that mathematical artists are authentic, valued participants.

Art for better teaching. Our students engage with the activities we plan for them, receiving thousands of cues about what we think mathematics is. Too many generations of students have been taught that the work-product of a mathematics class is a set of answers. Online teaching has everyone talking about student cheating. Students

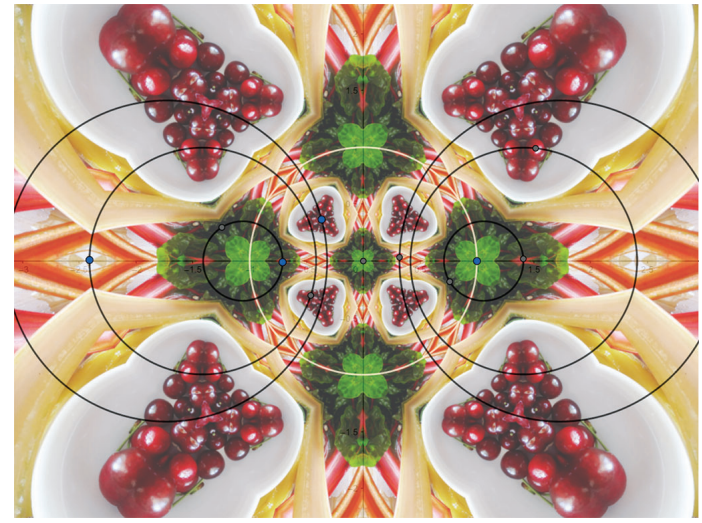

Figure 6. Using compass and straightedge tools to test the octahedral symmetry of a pattern.

who have been asked to deliver answers may well take short-cuts to produce them. Suppose our assignments required more creative engagement?

Here's one short example of an art-based assignment for students in my "Survey of Geometry" class, suddenly converted to an online course last spring. We were in the later chapters of Michael Hitchman's book, Geometry, with an Introduction to Cosmic Topology and students already knew how to create compass-and-straightedge tools in Geogebra to model spherical geometry, as viewed by stereographic projection to the complex plane.

Students were asked to use Peter Stampfli's delightful Spherical Kaleidoscope [Sta18] to create a pattern with polyhedral symmetry, position it correctly in a Geogebra sketch, and then draw on it in such a way as to show their understanding of the symmetry of the pattern. My own solution, in Figure 6, shows a pattern with octahedral symmetry, created with the kaleidoscope from a photograph of red cherries in a bowl next to some rainbow chard, viewed by stereographic projection. The cream-colored circle is a great circle that passes through four of the vertices of the octahedron, colored with the deep green of the chard. (An unseen vertex has been blown away to infinity.) The various black circles represent small circles on the sphere, centered at two of the octahedral vertices. Two of them show that the octahedral face centers-centers of 3-fold rotational symmetry colored red by the cherries-are equidistant from the vertices, as they should be. Another pair show that the edge centers-centers of 2-fold symmetry colored by the chard stems-are likewise equidistant from the vertices.

Students enjoyed creating their own patterns. Those unsuccessful in presenting a coherent display like this one were given the opportunity to try again. It was a popular assignment during difficult times.

Serving mathematics itself. Mathematical art, like mathematical exposition, does something that badly needs doing in mathematics: It helps us see the whole. Twentieth 
century mathematics, in my opinion, looked like a tangle of branches ever expanding outward, with little effort to connect back to the original inquiries that sparked investigation of an area. Since mathematical accomplishments are valued largely by the experts in narrow fields, it has been perhaps too easy to lose sight of their value to the larger community.

Both exposition and art call for us to put things together, to connect ideas back to the trunk of mathematics. If these creative endeavors are not valued by the academy, we lose opportunities to explain and defend our activities to the rest of humanity. Furthermore, exposition and art both bring energy to mathematicians of all stripes by creating a common feeling that, yes, this is a truly beautiful part of the human experience.

\section{Conclusion}

If I have convinced you that mathematical art is a discipline that deserves recognition, what steps might you take to promote it? Anyone teaching mathematics at any level can help their students join the exciting expansion of mathematical art. You could welcome your students' artistic expressions into the classroom or ask them to find an artwork relevant to their classwork at the Bridges galleries (ga11ery.bridgesmathart.org/). If you had just a small budget, you could purchase some mathematical art and invite the artist to give a talk about it.

If you wish to get involved yourself, there are many ways to begin and people ready to help. Energized by Bridges 2017 in Waterloo, Vincent Matsko, then at the University of San Francisco, began to organize monthly meetings for mathematical artists in the San Francisco Bay Area. This group continues today as BAAM! (Bay Area Art and Math, with an exlamation point just because). During the pandemic, we began to meet virtually, so that people like Roger Antonsen (University of Oslo, Norway), who energized the ICERM semester by his ability to code a tool to visualize a concept by the time the talk about it ended, can attend from afar. Our group is just one example of a local community that welcomes new participants in the field. Contact me if you would like to join.

An important step in my own career was the invitation to serve as Benedict Distinguished Professor at Carleton College, where I taught the course whose list of topics became the chapters of my book. If your department has the resources to issue such an invitation, consider how a mathematical artist would enrich your community. If you already have a mathematical artist in your department, you can speak up to dispel doubts about the value of their contributions. In other words, you can support the idea that this work, having passed peer review, is "real" and should "count" in the evaluation of scholarship.

The highest level of commitment would be to help create a position in your department for a mathematical artist. Mathematical artists open doors for potential mathematicians who may have been failed by conventional approaches. We show the public that our world cares about what they think, see, and know about mathematics. Mathematical artists can help instructors find engaging challenges that show students that mathematics has many kinds of beauty. Best of all, mathematical artists, whether by literal illustration or dreamy imaginings, have the potential to help everyone to better understand and enjoy mathematics itself.

ACKNOWLEDGMENTS. This work was supported in part by the National Science Foundation under Grant No. DMS-1439786 and the Alfred P. Sloan Foundation Grant No. G-2019-11406 while the author was in residence at the Institute for Computational and Experimental Research in Mathematics in Providence, RI, during the Illustrating Mathematics fall semester program.

\section{References}

[BF93] Thomas Banchoff and Frank Farris, Tangential and normal Euler numbers, complex points, and singularities of projections for oriented surfaces in four-space, Pacific J. Math. 161 (1993), no. 1, 1-24. MR1237138

[Dav20] Diana Davis, Illustrating mathematics, American Mathematical Society, Providence, RI, 2020.

[Far15] Frank A. Farris, Creating symmetry: The artful mathematics of wallpaper patterns, Princeton University Press, Princeton, NJ, 2015. MR3362188

[Far96] Frank A. Farris, Wheels on Wheels on Wheels-Surprising Symmetry, Math. Mag. 69 (1996), no. 3, 185-189. MR1573166

[Gam16] Lynn Gamwell, Mathematics + art: A cultural history, Princeton University Press, Princeton, NJ, 2016. With a foreword by Neil deGrasse Tyson. MR3445193

[Orn19] Stephen Ornes, Math art: Truth, beauty, and equations, Sterling, New York, NY, 2019.

[Sta18] Peter Stampfli, Spherical kaleidoscope app (2018). geometricolor.ch/images/geometricolor /spherica1KaleidoscopeApp.htm1.

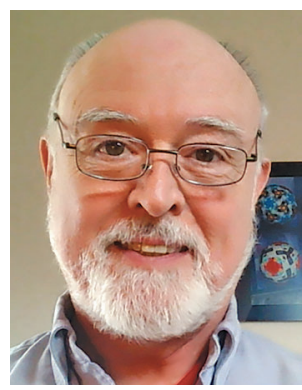

Frank A. Farris

Credits

Figures 1, 2, and 4-6 and photo of Frank A. Farris are courtesy of Frank A. Farris.

Figure 3 is courtesy of Susan Goldstine. 